\title{
Refractory Malignant Myoepithelioma
}

National Cancer Institute

\section{Source}

National Cancer Institute. Refractory Malignant Myoepithelioma. NCI Thesaurus. Code C162733.

A malignant myoepithelioma that does not respond to treatment. 